\title{
A Review on Comparative Study on the Structural Analysis and Design of Pre-Engineered Building [PEB] with Conventional Steel Building [CSB]
}

\author{
Mitaali Jayant Gilbile ${ }^{1}$, S. S. Mane ${ }^{2}$ \\ ${ }^{1}$ PG Student, Department Of Civil Engineering, PVPIT Budhgaon Sangli, India. \\ ${ }^{2}$ Associate Professor, Department Of Civil Engineering, PVPIT Budhgaon,Sangli, India.
}

\begin{abstract}
In this paper, an industrial structure (PEB \& CSB Frames) is analyzed and designed according to the Indian standards. Three models each for PEB and CSB are considered having different widths and a parametric study is carried out to access the performance of the models in terms of weight comparison, cost comparison and time comparison. In this study, an industrial structure (factory truss) is analyzed and designed according to the Indian standards, IS 800-1984, IS 800-2007. The various loads like dead, live, wind, seismic and snow loads according as per IS codes are considered for the present work for relative study of Pre-Engineered Buildings (PEB) and Conventional Steel Building (CSB). To compare the consequences of the numerous parametric studies to perform the variations in terms of shear force, support reaction, weight correlation and cost evaluation.
\end{abstract}

Key Words: Pre-engineered building (PEB), Conventional steel Building (CSB)

\section{INTRODUCTION}

Steel is the material of choice for design because it is ductile and flexible. Steel members have high strength per unit weight and the properties of the steel members mostly do not change with time. In recent years, the introduction of Pre Engineered Building (PEB) design of structures has helped in optimized design. The construction of PEB in the place of Conventional Steel Building (CSB) design concept resulted in many advantages as the members are design as per bending moment diagram and thus reducing the material requirement. This methodology is versatile not only due to its quality predesigning and prefabrication, but also due to its light weight and economical construction. If we go for regular steel structures, time frame will be more, and also cost will be more, and both together i.e. time and cost, makes it uneconomical. This concept has many advantages over the Conventional Steel Building (CSB) concept of buildings with roof truss.

In this paper, a comparison will be made between Pre Engineered buildings and conventional steel structures.

\section{CATEGORIES OF BUILDING}

Over the past decade a healthy growth and increased demand has been seen in the construction of residential buildings, institutional buildings, commercial buildings and infrastructure sectors. The earlier period structures were much more simple and unsophisticated compared to the modern day structures. The major modification seen in today's structures is that they are taller loftier and thinner compared to that of olden days structures. The construction of structures has seen a, continuous economic competition between concrete, steel and other materials.

\section{Reinforced Concrete Structures:}

These are the structures in which steel bars are used to improve the qualities of concrete. Over the recent years it has been used as a cost-effective construction material in various forms. It is possible to construct these structures with the help of local labors as cement; fine aggregates, coarse aggregates, water etc are widely accessible.

\section{Conventional Steel Structures:}

In today's world, steel is bringing elegance, artistry and is functioning in endless ways contributing to new solutions for the construction of formidable structures, which were once unthinkable. Steel offers speedy construction right from the start. Due to its important characteristics like ductility, flexibility etc, steel is been widely used in the construction industry. It bends under the application of heavy loads rather than undergoing crushing and crumbling. Due to its strength, less rate, stability, flexibility and recyclability, it makes a great choice to use steel in construction. It is also seen that steel has some reserve strength in them. The conventional steel buildings are stable. Usually hot-rolled structural members are used in these buildings. Here the members are fabricated in factories and then transported to the site. The changes can be made during the erection by welding and cutting process. Normally trusses are used in this system.

\section{Pre-Engineered Buildings [PEB]:}

These are produced in the plant, itself. Here according to the requirements of the customer the manufacturing of the members is done. The components are made in completely ready condition for transportation. These are then sent to the site and then the erection process starts. The manufacturing process doesn't takes place at the site. The pre-engineered buildings are normally constructed for office, shop fronts, ware houses etc. Here the extra amount of steel is avoided because the sections are tapered according to the bending moment diagram.

\section{LITERATURE REVIEW}

1 Phatangare Roshani Rambhau, Dr.Wakchaure M.R. ${ }^{[1]}$ have studied behavior of roof trusses and purlins for large spans for material saving and economy. They have designed and compared two trusses for internal forces, co- 
existing moments and shear forces at critical cross sections. The studies states that the truss provided along length required less material as compare to truss provided along width of span. They have concluded that cost of construction is less as compare to truss placed along width of span \& this gives new method of truss placing in roofing system.

2 Hemant Sharma ${ }^{[2]}$ have studied comparison and analysis of PEB \& CSB staad Pro. In this case study comparison for industrial building is done for bending moments at different sections \& the results are compared for economy and time saving in construction.After analysis and design the report is concluded with $37 \%$ material saving in case of PEB than that of CSB.

3 Abhyuday Titiksh, Abhinav Dewangan, Ankur Khandelwal , Akshay Sharma ${ }^{[3]}$ "This paper mainly focuses on the advantages of pre-engineered buildings over conventionally designed buildings. The different fields of comparison mainly constitute its cost effectiveness, time saving, future scope, subtleness and economy of pre-engineered buildings over conventionally engineered buildings and its importance in developing nations like India. This case study for Industrial Shed based on the review \& studies which shows experimental and analytical studies carried out in this field. The result shows that these structures are economical, energy efficient and flexible in design".

4 Milind Bhojkar ,Milind Darade ${ }^{[4]}$ have studied that the cost can be minimized by utilizing optimum cross-section of steel. Also they have shown the various application of PEB. They showed that for low rise building, PEB is found to be more economical than CSB. From their studies they concluded that CSB is $26 \%$ heavier than PEB and also PEB is $30 \%$ economical."

5 Nitin Vishwakarma, Hardik Tayal ${ }^{[5]}$ have studied Pre Engineered and Conventional Steel Building concept of Design for Industrial building of $18 \mathrm{~m}$ long span located in Palwal near New Delhi, India. A fully stressed design of Pre Engineered Building with members of varying thickness, Conventional Building with Conventional Steel members and Conventional Building with different hollow and compound section are discussed in paper. A total of five cases are studied. It concluded that more than $\mathrm{PEB}$, truss bracing gives the best suited result based on the economical possibility and the structural safety. They have also concluded that the material cost is reduced by $40 \%$ to $42 \%$ from PEB portal, when only tube sections are adopted in portal with truss pattern.

6 Sagar Wankhade and Prof. Dr. P. S. Pajgade ${ }^{[6]}$ have given importance of using pre-engineered-structure in construction, mainly for single storey building. They also have shown that conventional steel-structure has disadvantages compared to pre-engineered-structure. They have done comparative study of pre-engineeredbuilding with conventional steel-building. From their studies they have found that pre-engineered building can be designed using simple procedures. Also they concluded that pre-engineered-building has various advantages over conventional steel-building in terms of cost, speed of construction etc
7 Vivek Thakre and Mr. Laxmikant Vairagade ${ }^{[7]}$ have shown that there are many advantages of pre-engineeredbuildings having single storey especially including economy and ease of fabrication. Here they have analyzed and designed an industrial structure according to IS codes 800-1984, IS 800-2007 and by MBMA-96 and AISC-89. Later they have also compared the economy which is in terms of comparison of weight between IS codes and American codes. From their research they have concluded that the design of pre-engineered-structures is done by simple procedures with respect to IS codes. They have also found out that there are various advantages of preengineered structures over conventional steel-structures in terms of cost, weight, erection etc

8 Swati Wakchaure and N.C.Dubey ${ }^{[8]}$ have shown that by using preengineered-structure in construction, there are various advantages because according to the bending moment diagram, the designing of members is done. As a result, the steel is reduced. They have analyzed and studied according to IS 800-2007 and IS 800-1984 \& the comparison of pre-engineered-structure with conventional steel-structure is done. They have also compared the weight of both the structures. From their studies they concluded that conventional steel-structure is $30 \%$ heavier than pre-engineered-structure and as a result the size of foundation is reduced of pre-engineered-structure.

\section{COMPARISON OF CSB AND PEB}

\subsection{Advantages of CSB:}

- Steel can be produced taking into account all the tolerances and specifications and it is structurally stable.

- Steel is energy efficient and it can also be recycled.

- Steel is not easily susceptible to warping, bending, twisting or buckling. As a result it can be easily modified. Also it is easy to install.

- Steel is economical and seldom fluctuates in rates.

- Steel requires low maintenance and also has good quality of construction.

- In case of cyclone prone areas, the steel structures are found to be ideal.

- It has low weight to strength ratio as compared to concrete.

\subsection{Limitations of CSB:}

- Steel is prone to corrosion when it comes in contact with air, water etc. They need to be painted frequently.

- Steel has very less immunity against fire ascompared to concrete.

- The energy of steel is drastically reduced when it is subjected to fire.

- The steel sections cannot be molded into any direction we want, but only the existing sections can be used 

4.3 Applications of CSB:
- Commercial Buildings
- Ware-Houses
- Garages
- Manufacturing facilities
- Churches

\subsection{Advantages of PEB:}

- Reduced Time of Construction

- Economical

- Freedom in expansion

- Suitable for longer span.

- Control in quality.

- Less maintenance

- Availability from single source

\subsection{Benefits of PEB :}

- Easily expanded or modified in future.

- Resistant to all types of weathers and fires.

- Economical design, thereby reducing the overall weight.

- Good quality, manufacturing and erection, therefore the project time is saved by $30 \%-40 \%$.

- Faster delivery and Construction.

- Less maintenance cost.

- It can be disassembled and shifted easily.

- It is environmental friendly.

- Rain water harvesting can be carried out with the help of gutters.

\subsection{Applications of PEB:}

- Industrial Sheds

- Offices

- Petrol bunks

- Schools

- Railway stations

- Ware-Houses

\section{CONCLUSIONS}

From past studies the PEB structures are prove to be more economical and results in material saving. The implementation of PEB is increasing but use if PEB is less than expected. The researches show that PEB structures are easy to design. These designs are efficient and results in speedy construction. These structures are more reliable than CSB. Hence the more research required for more outputs for design methods and reducing material in PEB structures

\section{REFERENCES}

[1] Sagar Wankhade and Prof. Dr. P. S. Pajgade, "Review Paper on Comparison of Conventional Steel Building \& Pre-Engineering Building", International Journal of Research in Advent Technology, Volume 2, Number 5, E-ISSN: 2321-9637

[2] Phatangare Roshani Rambhau, Dr.Wakchaure M.R. 'A Review Paper On Alternate Design Of Roofing Sysytem' International Journal Of Engineering Sciences \& Research Technology feb,2017

[3] Hemant Sharma 'A Comparative Study on Analysis \& Design of Pre-Engineered \& Conventional Industrial Building' International Journal for Innovative Research in Science \& Technology| Volume 3 | Issue 10 | March 2017

[4] Abhyuday Titiksh, Abhinav Dewangan, Ankur Khandelwal, Akshay Sharma 'Comparative Study of Conventional Steel Building and PreEngineered Building to be used as an Industrial Shed' Abhinav Dewangan et al. Int. Journal of Engineering Research and Applications ISSN: 2248-9622, Vol. 5, Issue 11, (Part - 2) November 2015

[5] Milind Bhojkar ,Milind Darade 'Comparison of Pre Engineering Building and Steel Building with Cost and Time Effectiveness' IJISET - International Journal of Innovative Science, Engineering \& Technology, Vol. 1 Issue 10, December 2014

[6] Nitin Vishwakarma, Hardik Tayal 'Optimization of Industrial Building using Pre-Engineering Building and Conventional Steel Building by Fully Stressed Design'International Journal of Applied Engineering Research ISSN 0973-4562 Volume 13, Number 20 (2018)

[7] Vivek Thakre and Laxmikant Vairagade (2016), "Analysis and Cost Comparative study of conventional Industrial building with PEB structure", Journal of Information, Knowledge and Research in Civil Engineering, ISSN 0975 - 6744

[8] Quazi Syed Shujat, Ravindra Desai 'Comparative Study of Design of Industrial Warehouse Using CSB, PEB and Tubular Sections' Quazi Syed Shujat Int. Journal of Engineering Research and Application ISSN : 2248-9622, Vol. 8, Issue5 (Part -I) April 2018 